\title{
Comparison of Automated Quantitative Coronary Angiography with Caliper Measurements of Percent Diameter Stenosis
}

\author{
Steven J. Kalbfleisch, MD, Mark J. McGillem, BS, Ibraim M.F. Pinto, MD, \\ Kevin M. Kavanaugh, MD, Scott F. DeBoe, BS, and G.B. John Mancini, MD
}

\begin{abstract}
Measurement of coronary artery stenosis is an invaluable tool in the study of coronary artery disease. Clinical trials and even day-to-day decision making should ideally be based on accurate and reproducible quantitative methods. Quantitative coronary angiography (QCA) using digital angiographic techniques has been shown to fulfill these requirements. Yet many laboratories have abandoned visual analysis in favor of the intermediate quantitative approach involving hand-held calipers. Thus, the purpose of this study was to determine the relation between QCA and the commonly used caliper measurements. Percent stenosis was assessed in 155 lesions using 3 techniques: QCA, caliper measures from a 35-mm cine viewer (cine) and caliper measures from a video display (CRT), Good overall correlation was noted among the 3 different techniques $(r \geq 0.72)$. Both of the caliper methods underestimated QCA for stenosis $\geq 75 \%$ ( $p \leq 0.001)$ and overestimated stenosis $<75 \%(p<0.05)$. Reproducibility assessed in 52 lesions by independent observers showed QCA to be superior $(r=0.95)$ to either of the caliper measurements (cine: $r=0.63$; CRT: $r=0.73$ ). Therefore, the commonly used caliper method is not an adequate substitute for QCA because overestimation of noncritical stenoses and underestimation of severe stenoses may occur and the measurements have poor reproducibility. These factors definitely preclude its use in rigorous clinical trials. Moreover, since they do not appear to overcome known deficiencies of visual analysis, caliper measurements for day-to-day clinical use must also be seriously questioned.
\end{abstract}

(Am J Cardiod 1990;65:1181-1184)

From the Department of Internal Medicine, Division of Cardiology, University of Michigan and Veterans Administration Medical Centers, Ann Arbor, Michigan. Manuscript received October 25, 1989; revised manuscript received and accepted January 22, 1990.

Address for reprints: G.B. John Mancini, MD, Division of Cardiology (111A), Veterans Administration Medical Center, 2215 Fuller Road, Ann Arbor, Michigan 48105.
$(1$ uantitation of coronary stenosis is an important practice in cardiology from both a clinical and research standpoint. Various techniques with differing degrees of sophistication are used to measure the amount of luminal narrowing. Visual inspection, hand-held calipers and automated quantitative digital angiographic programs are examples of these different methods.

For use in a research setting and ideally in a clinical setting, a highly reproducible and accurate method is needed. Since visual inspection of $35-\mathrm{mm}$ cinefilm has been shown to have a very high degree of inter- and intraobserver variability, ${ }^{1-4}$ as well as a great degree of inaccuracy, ${ }^{5-8}$ it is clearly not adequate for clinical studies. Quantitative coronary angiography (QCA) performed with the use of digital angiographic techniques and computer analysis has been shown to have excellent reproducibility and accuracy. ${ }^{9-12}$ Although earlier methods of QCA were tedious and time consuming, ${ }^{13,14}$ more recently developed programs are easy to use and efficient; they can perform on-line digital image analysis in roughly 1 minute. ${ }^{9}$

Caliper measurements are commonly used for quantitation of percent stenosis due to the simplicity of the procedure and low costs. Accordingly, it is important to document the performance characteristics of caliper measurements as well as to determine whether sophisticated QCA is substantially better or worse. We undertook the present study to compare one of the more advanced QCA programs developed and validated at this laboratory $9,15,16$ with hand-held caliper measurements. To avoid the issue of comparability of cinefilm versus on-line digital acquisition, we performed analyses using only images acquired on $35-\mathrm{mm}$ cinefilm. These were analyzed by QCA, by caliper measurements from a standard cine $35-\mathrm{mm}$ viewer (cine) and by caliper measures from a standard video screen (CRT). The latter was included because caliper measures from video screens are also common in catheterization laboratories in the absence of QCA and may be prone to additional errors, such as parallax, inherent in the use of CRT displays.

\section{METHODS}

Images of 155 coronary artery lesions were selected from studies analyzed at the Ann Arbor Veterans Administration Medical Center. Each lesion was quantitated with respect to percent stenosis using a previously validated QCA program ${ }^{9,15-17}$ and hand-held calipers applied to cine and a CRT. Image and film quality was 
determined by the standard of the laboratory performing the catheterization and reviewed by the core laboratory to ensure diagnostic adequacy. To be eligible for analysis it was required that the image show the entire lesion without overlap of other vessels and that a straight portion of the shaft of the angiographic catheter was within the field of view.

Quantitative coronary anglography program: All angiograms were projected on a cine $35-\mathrm{mm}$ viewer (Vanguard Instruments, model XR-15) optically coupled to a video camera at $2.4: 1$ optical magnification; the video signal was digitized at $512 \times 512 \times 8$ bit resolution onto a digital angiographic computer (ADAC Laboratories, model DPS-4100C). Images were magnified 2-fold using bilinear interpolation. The lesion of interest was determined by the operator through placement of a variable sized circle around this area on the digitized angiogram, and the edges were then outlined by the automatic edge detection program. A similar process was performed on a portion of the catheter shaft displayed on the angiogram for use in calibration when absolute lesion dimensions are needed. The program automatically displayed the maximum percent stenosis along with other measurements of luminal narrowing.

Caliper method: Hand-held calipers were used to measure maximum percent stenosis for each lesion displayed on both cine (Vanguard Instruments, model XR15) and the digitized angiograms projected on CRT (10 $\times 7$ inches, 525 lines, R5170 monochrome video monitor). The brightness and contrast controls of the video screen were set by the operator based on individual preferences. The operators were required to define and measure both the normal arterial segments and the point of maximal stenosis for each lesion displayed and to calculate the percent diameter stenosis. The cineframes analyzed were the same for both QCA and CRT and showed the lesion in its most severe view. For cine the frame was selected to match the QCA and CRT images as closely as possible.

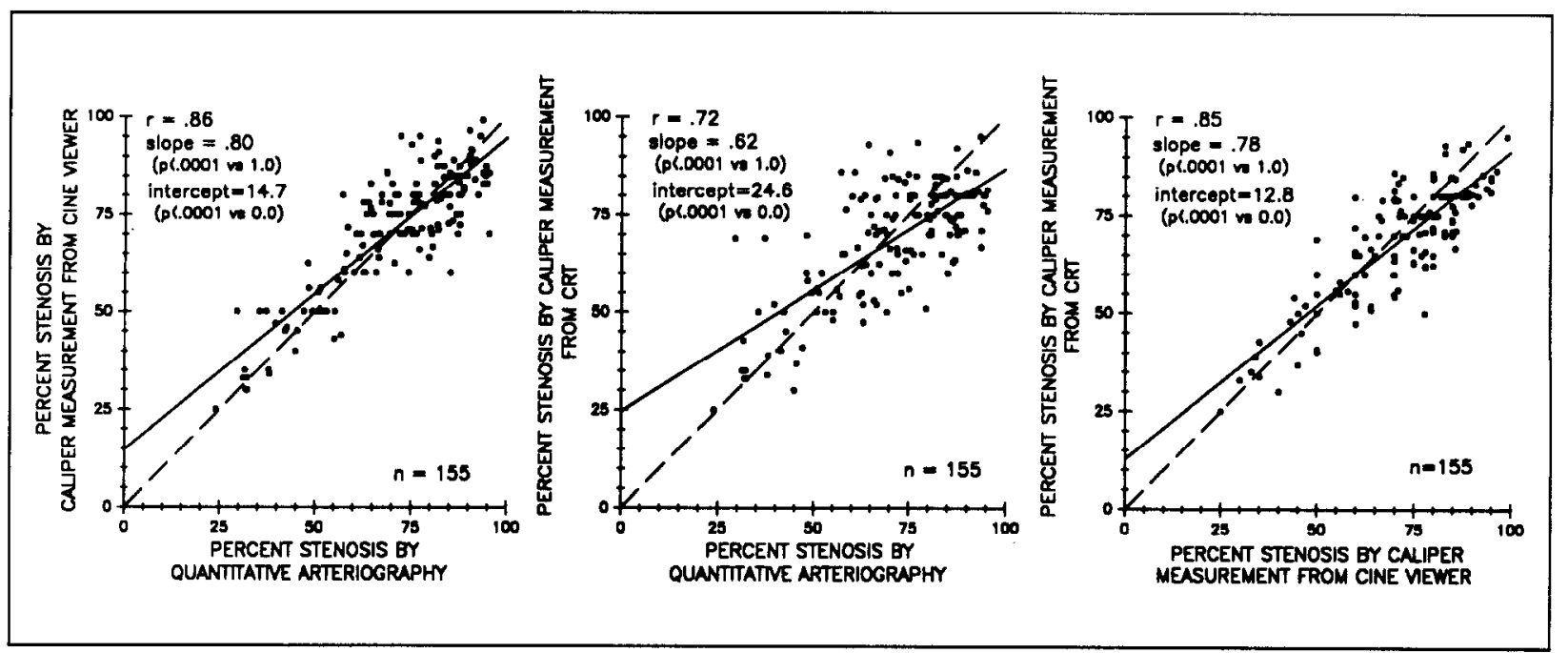

FIGURE 1. Scatter plot with linear regression analyses comparing the 3 methods. The dashed line on each graph is the line of unity (stope $=1 ;$ y intercept $=0$ ).

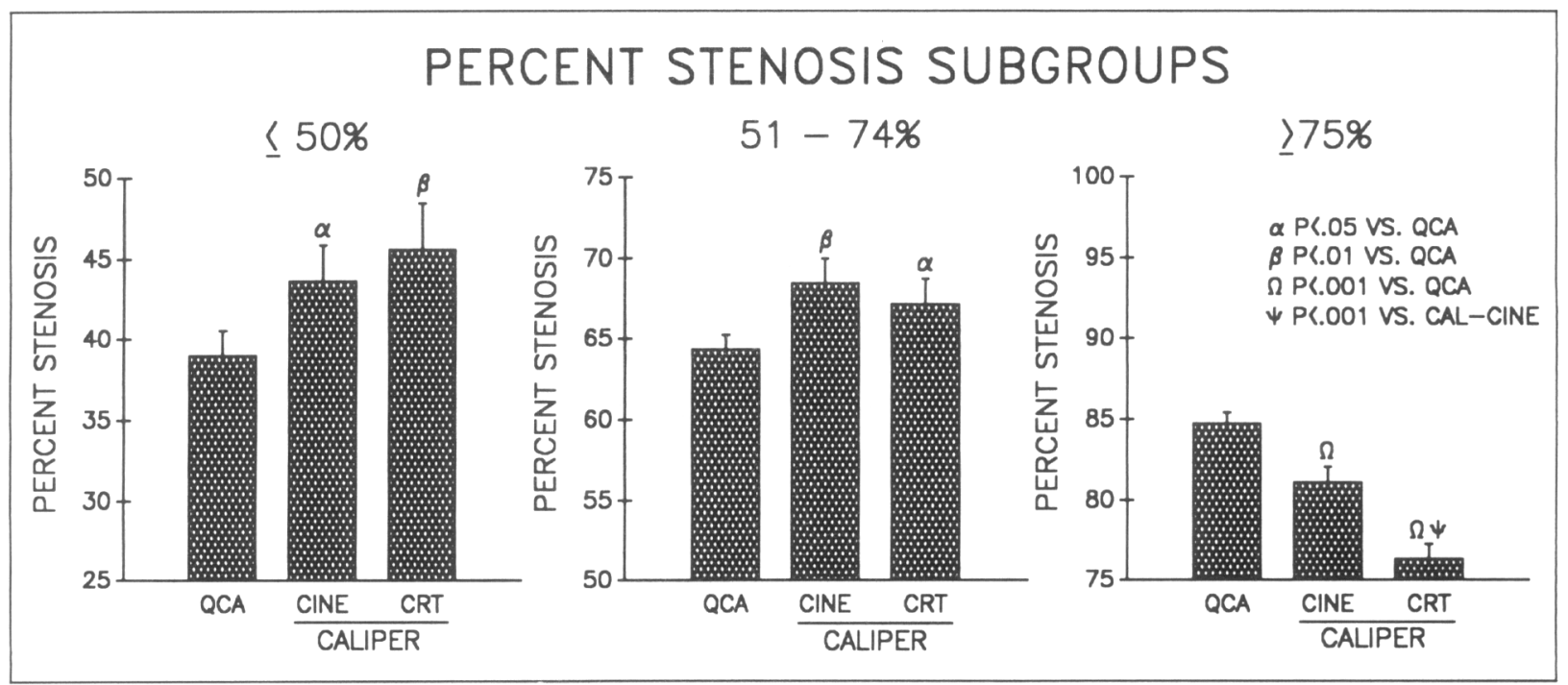

FIGURE 2. Histogram plot comparing the 3 methods using subgroups of percent stenods. CAL = calper; cine = 35 -mm cinefin viewer; CRT = video display; QCA = quantitative coronary anglography. 
Method comparisons: Each method was compared to the others for all 155 lesions using standard linear regression analysis. Slopes and intercepts of the regression models were compared to values of 1.0 and 0.0 , respectively, to ascertain if they were significantly different using $t$ tests. The methods were then also compared using clinically relevant subgroups of percent stenosis ( $\leq 50 \%, 51 \%$ to $74 \%, \geq 75 \%$ ) based on QCA measurements to determine whether the caliper methods systematically under- or overestimated the QCA measurements. These comparisons were done using a repeated measure analysis of variance ${ }^{18}$ followed by Newman-Kuels simultaneous multiple comparisons. ${ }^{19} \mathrm{Re}-$ producibility of the 3 techniques was assessed by a second independent observer who reanalyzed 52 lesions. Correlation coefficients and the standard deviation of the mean differences were determined. The correlation coefficients of the different methods were then compared using Fisher's $Z$ transformation ${ }^{20}$ and the standard deviations of the mean difference were compared using an $\mathrm{F}$ test of the ratio of the variances. ${ }^{18}$

\section{RESULTS}

The 3 methods showed good overall correlation by linear regression analysis (Figure 1): QCA versus caliper measurements from cine, $r=0.86$; $Q C A$ versus caliper measurements from CRT, $r=0.72$ and caliper measurements from cine versus caliper measurements from CRT, $r=0.85$. Comparison of the linear regression models for QCA versus both of the caliper methods with the line of unity (slope $=1, y$ intercept $=0$ ) showed them to be significantly different from unity for both slope and $y$ intercept $(p<0.0001)$. This comparison demonstrated that for both of the caliper methods versus QCA there was a systematic overestimation of noncritical stenoses and underestimation of severe stenoses as indicated by the position of the linear regression lines relative to the line of unity (Figure 1). This same relation was also noted for caliper measurements from cine versus CRT, in which both the slope and $y$ intercept were significantly different from the line of unity $(p<0.0001)$. The position of the linear regression line with the line of unity also indicated that there was a systematic overestimation of the less severe stenoses and underestimation of the more severe stenoses by the CRT measurements (Figure 1). This comparison indicates that there are inherent differences in cine caliper measurements compared with those from CRT.

Comparison of the methods using percent stenosis subgroups ( $\leq 50 \%, 51 \%$ to $74 \%, \geq 75 \%$ ) based on QCA measurements also demonstrated differences between the techniques (Figure 2). For QCA versus cine caliper measurements, caliper measurements overestimated QCA for stenoses $<50 \%$ ( $\mathrm{p}<0.05$ ) and $51 \%$ to $74 \%$ (p $<0.01$ ), and underestimated QCA for stenoses $\geq 75 \%$ ( $\mathrm{p}$ $<0.001)$. When QCA was compared to CRT caliper measurements, an identical pattern was observed with caliper measurements significantly overestimating less severe stenoses $(<75 \%)$ and underestimating the more severe stenoses $(\geq 75 \%)$. Of practical importance, the caliper measures from both cine and CRT were equiva- lent except for stenoses $\geq 75 \%$, which were underestimated by CRT caliper measures ( $\mathrm{p}<0.001$ ).

Reproducibility assessed in 52 lesions by independent observers showed significant differences. Linear regression analysis found QCA to be highly reproducible $(\mathrm{r}=0.95$, standard deviation of the mean differences $=$ 4.6). In contrast, neither caliper method was: cine caliper measurements, $r=0.63$, standard deviation of the mean differences $=12.4$, and CRT caliper measurements, $r=0.73$, standard deviation of the mean differences $=9.5$. The differences in $r$ value and standard deviation of the mean differences between QCA and the 2 caliper methods was significant $(p<0.001)$. The standard deviation of the mean differences was also significantly greater for cine versus CRT caliper measurements $(\mathrm{p}<0.05)$

\section{DISCUSSION}

Accurate and reproducible assessment of the severity of coronary lesion narrowing is vitally important: it is the basis for the majority of current clinical decisions regarding revascularization. Most cardiologists still depend on visual inspection for percent stenosis, which has been shown to have poor reproducibility ${ }^{1-4}$ and an unacceptable degree of inaccuracy. ${ }^{5-8}$ Because of the problems with visual inspection, caliper measurements have been adopted in an attempt to be more rigorous in the quantitation of lesion severity. Other more sophisticated approaches use digital angiography and computer programs for quantitation of coronary stenosis. ${ }^{9,13}$ The caliper method is also attractive because of its convenience and low cost.

Quantitative angiography using digital angiographic techniques coupled with computer analysis has been shown to be both accurate and reproducible. ${ }^{9,10,12,13,21}$ This type of analysis has demonstrated the ability to determine the physiologic significance of a coronary stenosis, ${ }^{9,22,23}$ predict the potential for ventricular functional recovery or rethrombosis after thrombolytic therapy, ${ }^{24,25}$ and assess responses to other interventions such as angioplasty or lipid-altering therapy. ${ }^{21}$ The QCA method used in this study has undergone extensive validation testing using both in vitro and in vivo phantom models, which showed excellent correlation between measured and actual luminal diameter $(r \geq 0.87) .9,10$ Some previous comparisons of digitized angiograms with conventional $35-\mathrm{mm}$ cinefilm have not used the automatic edge detection algorithms and computer-assisted programs for quantitation. Four prior studies used either visual inspection or caliper measurements in their comparison of cinefilm with digitized angiograms. ${ }^{26-29}$ Each of these studies found that digitized angiograms compared favorably with cinefilm with no loss of image quality or significant increase in variability. Another study has seemed to question the utility of digital radiographic techniques as a substitute for $35-\mathrm{mm}$ cinefilm, but this study also used only hand-held manual caliper measurements. ${ }^{30}$ The only criticism of digital angiography was that there was a modest overestimation of stenosis $<50 \%$ as measured by cinefilm analysis. The present study indicates that there are inherent differences in 
cine caliper measurements compared with those from a CRT and that the conclusion of studies comparing digital angiograms with cinefilm may be affected by this measurement bias.

Our study used a quantitative digital angiographic program shown to be both accurate and reproducible and compared these results to a commonly used quantitative measure of stenoses, caliper measurements. Caliper measurements are prone to errors due to parallax, are generally performed on nonmagnified images and require much operator interaction to define both normal and minimal diameter segments. Parallax errors are potentially even more problematic when video images are viewed on CRT screens. Our results provide specific information on the relative performance of caliper and QCA measures and, moreover, demonstrate difficulties arising from caliper measures from CRT screens. Caliper measurements from either cine or CRT are comparable in assessing stenosis severity $(r=0.85)$ but $C R T$ caliper measures underestimate the severity of lesions $\geq 75 \%$.

Our most important result is that state of the art quantitative digital angiography is substantially better than caliper measurements from either cine or CRT in 2 respects. The QCA program had much better reproducibility $(r=0.95)$ than caliper measurements from cine $(r=0.63)$ or CRT $(r=0.73)$. Second, the caliper measurements underestimated the more severe stenosis $(\geq 75 \%)$ and overestimated the less critical stenosis $(<75 \%)$. These findings have obvious and significant implications for both research studies and clinical practice. Study conclusions and clinical decisions are likely to be adversely affected by the lack of reproducibility and the systematic differences in judging stenosis severity. In this regard, caliper measurements cannot be considered to overcome any of the known limitations of visual inspection.

Acknowledgment: The authors wish to acknowledge the secretarial assistance of Penny Weaver.

\section{REFERENCES}

1. DeRouen TA, Murray JA, Owen W. Variability in the analysis of coronary arteriograms. Circulation 1977;55:324-328.

2. Detre KM, Wright E, Murphy ML, Takaro T. Observer agreement in evaluating coronary angiograms. Circulation 1975;52:979-983.

3. Zir LM, Miller SW, Dinsmore RE, Gilbert JP, Harthorne JW. Interobserver variability in coronary angiography. Circulation 1976;53:627-632.

4. Fisher LD, Judkins MP, Lesperance J, Cameron A, Swaye P, Ryan T, Maynard C, Bourassa M, Kennedy JW, Gosselin A, Kemp H, Faxon D, Wexler L, Davis KB. Reproducibility of coronary arteriographic reading in the coronary artery surgery study (CASS). Cathet Cardiovasc Diagn 1982:8:565-575.

5. Vlodaver Z, Frech R, Van Tassel RA, Edwards JE. Correlation of the antemortem coronary arteriogram and the postmortem specimen. Circulation 1973, 47:162-169.

6. Arnett EN, Isner JM, Redwood DR, Kent KM, Baker WP, Ackerstein H, Roberts WC. Coronary artery narrowing in coronary heart disease: comparison of cineangiographic and necropsy findings. Ann Intern Med 1979;91:350-356. 7. Grondin CM, Dyrda I, Pasternac A, Campeau L, Buurassa MG, Lesperance J.
Discrepancies between cineangiographic and postmortem findings in patients with coronary artery disease and recent myocardial revascularization. Circulation 1974:49:703-708.

8. Kemp HG, Evans H, Elliot WC, Gorlin R. Diagnostic accuracy of selective coronary cinearteriography. Circulation 1967:36:525-533.

9. Mancini GBJ, Simon SB, McGillem MJ, LeFree MT, Friedman HZ, Vogel RA. Automated quantitative coronary arteriography: morphologic and physiologic validation in vivo of a rapid digital angiographic method. Circulation $1987 ; 75: 452-460$

10. Mancini GBJ. Quantitative coronary arteriography: development of methods, limitations, and clinical applications. Am J Cardiac Imaging 1988:2:98-109.

11. Lefree MT, Simon SB, Sanz ML, Vogel RA, Mancini GBJ. Quantitative coronary angiography. In: Mancini GBJ, ed. Clinical Applications of Cardiac Digital Angiography. New York: Raven Press, 1988:219-239.

12. Sanz ML, Mancini GBJ, LeFree MT, Mickelson JK, Starling MR, Vogel RA, Topol EJ. Variability of quantitative digital subtraction coronary angiography before and after percutaneous transluminal coronary angioplasty. $\mathrm{Am} \mathrm{J}$ Cardiol 1987,60:55-60.

13. Brown GB, Bolson E, Frimer M, Dodge HT. Quantitative coronary arteriography: estimation of dimensions, hemodyrlarnic resistance and atheroma mass of coronary artery lesions using the arteriogram and digital computation. Circulation 1977;55:329-337.

14. Scoblionko DP, Brown G, Mitten S, Caldwell JH, Kennedy JW, Bolson EL Dodge HT. A new digital electronic caliper for measurement of coronary arterial stenosis: comparison with visual estimates and computer-assisted measurements. Am J Cardiol 1984:53:689-693.

15. LeFree MT, Simon SB, Lewis RJ, Bates ER, Vogel RA. Digital radiographic coronary artery quantification. Proceedings of the IEEE Computer Society. Comput Cardiol 1985;99-102.

16. LeFree MT, Simon SB, Mancini GBJ, Vogel RA. Digital radiographic assessment of coronary arterial geometric diameter and videodensiometric crosssectional area. Proc SPIE 1986:626:334-34I.

17. LeFree MT, Simon SB, Mancini GBJ, Bates ER, Vogel RA. A comparison of $35 \mathrm{~mm}$ cine film and digital radiographic image recording: implications for quantitative coronary arteriography. Invest Radiol 1988;23:176-182.

18. Netter J, Wasscrman W. Applicd lincar statistical models. Homewood, Illinois: Richard D. Irvin, 1974:16-17,745-746.

19. Miller RG Jr. Simultaneous Statistical Inference. New York: Springer Verlag, 1981:81-90

20. Snedecor GW, Cochman WG. Statistical Methods. Ames, lowa: The lowa State University Press, 1982:185-188.

21. Brown BG, Bolson EL, Dodge HT. Quantitative computer techniques for analyzing coronary arteriograms. Prog Cardiovasc Dis 1986;28:403-418.

22. McMahon MM, Brown BG, Cukingnan R, Rolett EL, Bolson E, Frimer M, Dodge HT. Quantitative coronary angiography: measurement of the "critical" stenosis in patients with unstable angina and single-vessel disease without collaterals. Circulation 1979:50:106-113.

23. Harrison DG, White CW, Hiratzka LF, Doty DB, Barnes DH, Eastham CL Marcus ML. The value of lesion cross-sectiun area determined by quantitative coronary angiography in assessing the physiologic significance of proximal left anterior descending coronary arterial stenoses. Circulation 1984;69:1111-1119. 24. Sheehan FH, Mathey DG, Schofer J, Dodge HT, Bolson E. Factors that determine recovery of left ventricular function after thrombolysis in patients with acute myocardial infarction. Circulation 1985;71:1121-1128.

25. Harrison DG, Ferguson DW, Collins SM, Skorton DJ, Fricksen EF, Kioschos JM, Marcus ML, White CW. Rethrombosis after reperfusion with streptokinase: importance of geometry of residual lesions. Circulation 1984,69:991-999. 26. Goldberg HL, Moses JW, Fisher J, Tamari I, Borer JS. Diagnostic accuracy of coronary angiography utilizing computer-based digital subtraction methods. Chest 1986;90:793-797.

27. Bray BE, Anderson FL, Hardin CW, Kruger RA, Sutton RB, Nelson JA. Digital subtraction coronary angiography using high-pass temporal filtration: a comparison with cineangiography. Cathet Cardiovasc Diagn 1985:11:17-24.

28. Tobis J, Nalcioglu O, Lloyd I, Johnston WD, Roeck W, Castelman E, Bauer B, Montelli S, Henry WL. Detection and quantitation of coronary artery stenoses from digital subtraction angiograms compared with 35 -millimeter film cineangiograms. Am J Cardiol 1984:54:489-496.

29. Vas R, Eigler N, Miyazono C, Pfaff MJ, Resser KJ, Weiss M, Nivatpumin T Whiting J, Forrester J. Digital quantification eliminates intraobserver and interobserver variability in the evaluation of coronary artery stenosis. Am J Cardio 1985;56.718-723.

30. Gurley JC, Nissen SE, Booth DC, Harrison M, Grayburn P, Elion JL DeMaria AN. Comparison of simultaneously performed digital and film-based angiography in the assessment of coronary artery disease. Circulation 1988;78:1411-1420. 